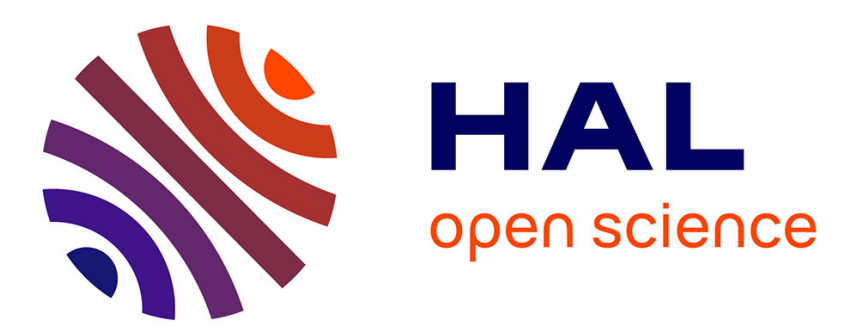

\title{
Experimental and modelling studies of the shape memory properties of amorphous polymer network composites
}

\author{
Juan Sebastian Arrieta, Julie Diani, Pierre Gilormini
}

\section{To cite this version:}

Juan Sebastian Arrieta, Julie Diani, Pierre Gilormini. Experimental and modelling studies of the shape memory properties of amorphous polymer network composites. Smart Materials and Structures, 2014, 23 (9), pp.095009. 10.1088/0964-1726/23/9/095009 . hal-01061146

HAL Id: hal-01061146

https://hal.science/hal-01061146

Submitted on 5 Sep 2014

HAL is a multi-disciplinary open access archive for the deposit and dissemination of scientific research documents, whether they are published or not. The documents may come from teaching and research institutions in France or abroad, or from public or private research centers.
L'archive ouverte pluridisciplinaire HAL, est destinée au dépôt et à la diffusion de documents scientifiques de niveau recherche, publiés ou non, émanant des établissements d'enseignement et de recherche français ou étrangers, des laboratoires publics ou privés. 


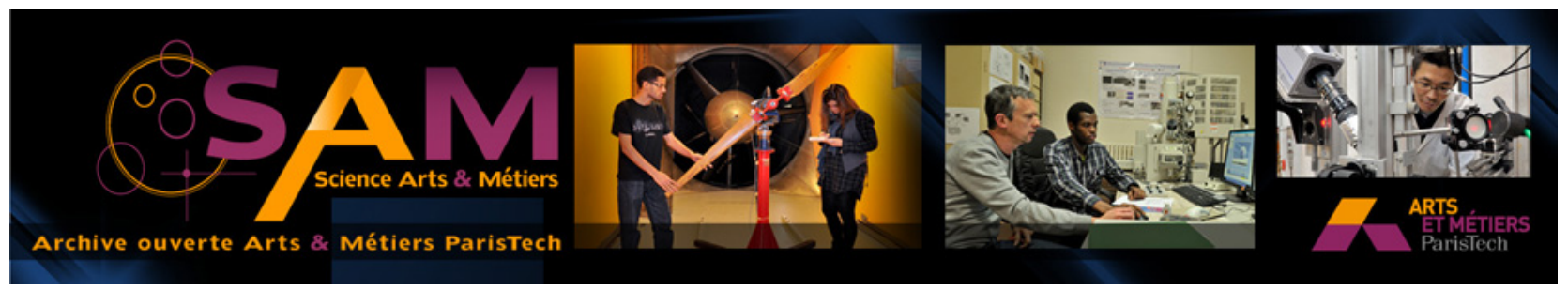

\section{Science Arts \& Métiers (SAM)}

is an open access repository that collects the work of Arts et Métiers ParisTech researchers and makes it freely available over the web where possible.

This is an author-deposited version published in: http://sam.ensam.eu

Handle ID: .http://hdl.handle.net/10985/8458

\section{To cite this version :}

Juan Sebastian ARRIETA, Julie DIANI, Pierre GILORMINI - Experimental and modelling studies of the shape memory properties of amorphous polymer network composites - Smart Materials and Structures - Vol. 23, n`9, p.095009 - 2014 


\title{
Experimental and modelling studies of the shape memory properties of amorphous polymer network composites
}

\author{
JS Arrieta, J Diani and P Gilormini \\ E-mail: juan-sebastian.arrieta-escobar@ensam.eu \\ Laboratoire PIMM, Arts et Metiers ParisTech, CNRS, 151 bd. de L'Hôpital, 75013 \\ Paris, France
}

\begin{abstract}
Shape memory polymer composites (SMPCs) have become an important leverage to improve the development of shape memory polymers (SMPs) applications. An amorphous SMP matrix has been filled with different types of reinforcements in this study. An experimental set of results is presented and then compared to 3D finite element simulations. Thermomechanical shape memory cycles were performed in uniaxial tension. The fillers effect was studied in stress-free and constrainedstrain recoveries. Experimental observations indicate complete shape recovery and put in evidence the increased sensitivity of constrained length stress recoveries to the heating ramp on the tested composites. The simulations reproduced a simplified periodic reinforced composite and use a model for the matrix material that has been previously tested on regular SMPs. The latter combines viscoelasticity at finite strain and time-temperature superposition. The simulations permit to represent the recovery properties of a reinforced SMP easily.
\end{abstract}

\section{Introduction}

For the past decade, shape memory polymers (SMPs) have drawn significant attention due to their ability to store a temporary shape and to recover a permanent shape under external stimuli. These materials have shown to be attractive due to their low weight, low processing cost, high deformability and the easy tailoring of the shape transition temperature. In order to broaden their potential applications, SMPs have been reinforced to enable athermal shape recovery stimuli and to increase their mechanical properties. The literature presents shape memory polymer composites (SMPCs) reinforced by fibres (Ohki et al. 2004, Lan et al. 2009, Ivens et al. 2011, Cuevas et al. 2012), carbon nanotubes (Miaudet et al. 2007, Lu et al. 2010, Ding et al. 2013, Li et al. 2013), nanoclay particles (Cao and Jana 2007), silicium carbide nanoparticles (Gall et al. 2002, Liu et al. 2004), fabrics (Zhang and Ni 2007, Ivens et al. 2011), etc. One may find more references in reviews on stimulus methods and applications for SMPCs (Leng et al. 2011, Meng and Li 2013, Liu et al. 2014). 
Several studies have focused on the development of athermal recovery stimuli (for instance Razzaq et al. 2007, Lu et al., 2010, Kumar et al. 2012, Leng et al. 2009), other studies have tested the shape recovery ability of SMPCs, in a qualitative way (Zhang and Ni 2007, Lan et al. 2009, Lu et al. 2010 among others) or a in quantitative one (Liu et al. 2004, Cao and Jana 2007, Miaudet et al. 2007, Ivens et al. 2011, Cuevas et al. 2012, Li et al. 2013). Few works report on stress recovery during strain-constrained heating (Gall et al. 2002, Fejos et al. 2012, Li et al. 2013), which may be of interest for actuator applications or for strain-constrained stress recovery applications. Albeit it would be interesting to be able to predict the recovery properties of SMPCs from the properties of the SMP matrix, few studies have compared the recovery kinetics of SMPCs to the recovery kinetics of their plain SMP matrices. Last, only Alexander et al. (2014) have proposed a model to estimate SMPC recovery properties from the recovery properties of the polymer matrix. The model consists of a $2 \mathrm{D}$ finite element representation of a periodic cell containing the cross-section of an infinite cylinder embedded in the thermoviscoelastic polymer matrix. Their model presents interesting features but unfortunately it has not been compared to actual experimental data.

The current study aims at testing and modelling the kinetics of the strain and stress recoveries of an amorphous acrylate network reinforced by various types of fillers. The plain acrylate and the composites were prepared in our lab. Fillers include micrometric glass bead, short and long glass fibres. Materials were submitted to stress-free strain recovery and strain-constrained stress recovery thermomechanical cycles in uniaxial tension. A relatively complete set of experimental data is reported, providing a better understanding of the effect of fillers on the behavior and the thermal kinetics of recovery of the SMPCs. Based on satisfactory modelling of the shape memory properties of the acrylate network reported by Arrieta et al. (2014a), finite element simulations of the glass bead reinforced acrylate were run in order to explore the interest of such simulations for predictive purpose in design applications. The composite is defined by a 3D periodic cell containing a spherical rigid bead surrounded by the viscoelastic acrylate satisfying to the time-temperature superposition property.

\section{Materials and experiments}

\subsection{Materials}

The amorphous acrylate network was obtained by photopolymerization of benzyl methacrylate (BMA) added with $550 \mathrm{~g} / \mathrm{mol}$ molar weight poly(ethylene glycol) dimethacrylate (PEGDMA) and $0.5 \%$ of 2-dimethoxy-2-phenylacetophenone (DMPA) used as photoinitiator following the protocol described in Safransky and Gall (2008). The composition was set to $90 \%$ moles of BMA and 10\% moles of PEGDMA. The plain amorphous polymer network presents a glass transition at $46^{\circ} \mathrm{C}$ when measured by DSC with a $10^{\circ} \mathrm{C} / \mathrm{min}$ heating ramp. Fillers were added to the polymer mix before the UV thermo activated polymerization (50 minutes in a UVP CL-100 oven). Three different 


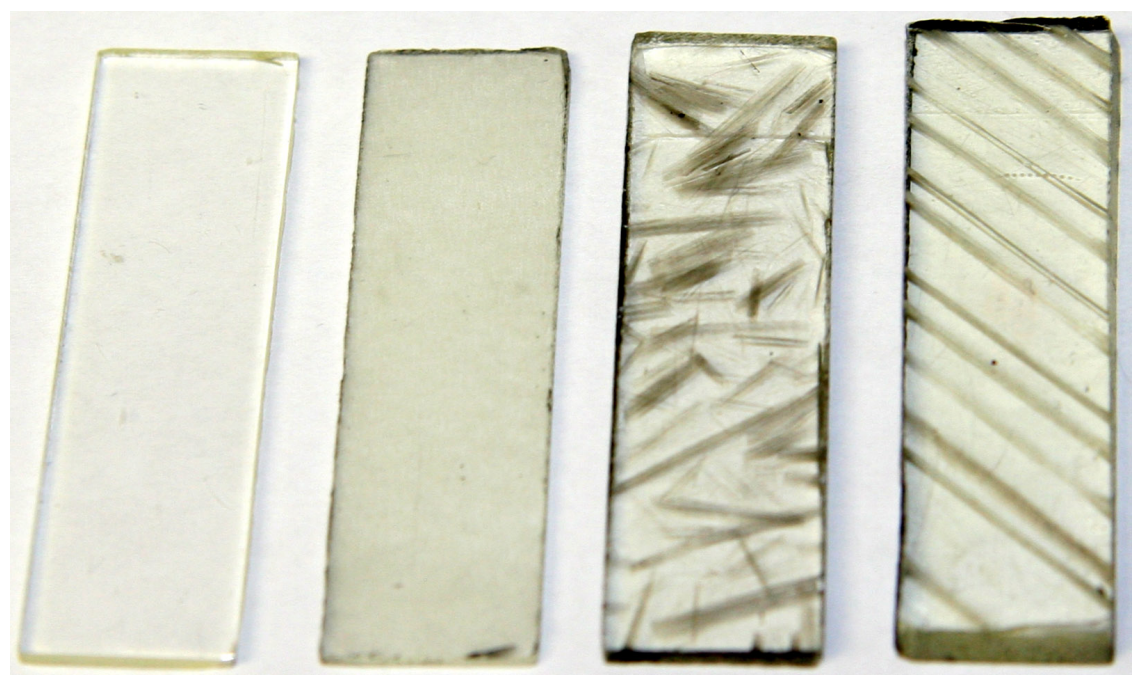

Figure 1. Material samples, from left to right: plain amorphous acrylate network, acrylate reinforced by glass bead, short glass fibres, and long glass fibres at $45^{\circ}$.

types of fillers were selected: polydisperse hollow glass bead of $55 \mu \mathrm{m}$ average diameter (Glasscell 25 from Sicomin), short glass fibres and continuous long glass fibres disposed at $45^{\circ}$. The various composites contain a mass fraction of $\sim 2 \%$ of glass bead, $\sim 5 \%$ of short glass fibres and $\sim 2 \%$ of continuous glass fibres respectively. Final products are rectangular plates of 1.3 to $2.1 \mathrm{~mm}$ thickness, which are then cut in rectangular samples for mechanical tests and analysis (figure 1).

\subsection{Mechanical characterization}

2.2.1. Uniaxial tension tests Uniaxial tension tests were performed in order to characterize the material stress-strain properties at various temperatures, to evaluate the filler reinforcement, and to estimate possible damage during loading. Tests were performed on an Instron 5881 testing machine equipped with a thermal chamber and local strain video extensometry. Crosshead speed was set to $10 \mathrm{~mm} / \mathrm{min}$ for all tests. Tests were run at $45^{\circ} \mathrm{C}$, which corresponds to a temperature within the glass transition, and at $65^{\circ} \mathrm{C}$ (above the glass transition). At $45^{\circ} \mathrm{C}$ the material should present high viscoelasticity while at $65^{\circ} \mathrm{C}$ the material is in the rubbery state and should present low viscoelasticity. Figure 2 presents the uniaxial stress-strain responses of the materials at $45^{\circ} \mathrm{C}$ and $65^{\circ} \mathrm{C}$. One notices the filler reinforcement at both temperatures.

Cyclic tests were run to detect possible damage during stretching. For this purpose, the materials were stretched up to $20 \%$, then unloaded and allowed recovering completely from the first stretch before reloading until break. The fibre glass composites were unable to stand a second loading phase, breaking systematically during the reloading step, evidencing serious damage at first stretch. To the contrary, the glass bead composite presented no appreciable damage as the initial modulus remained unchanged during the second loading (figure 3). It is to be noted that complete strain recoveries were obtained 

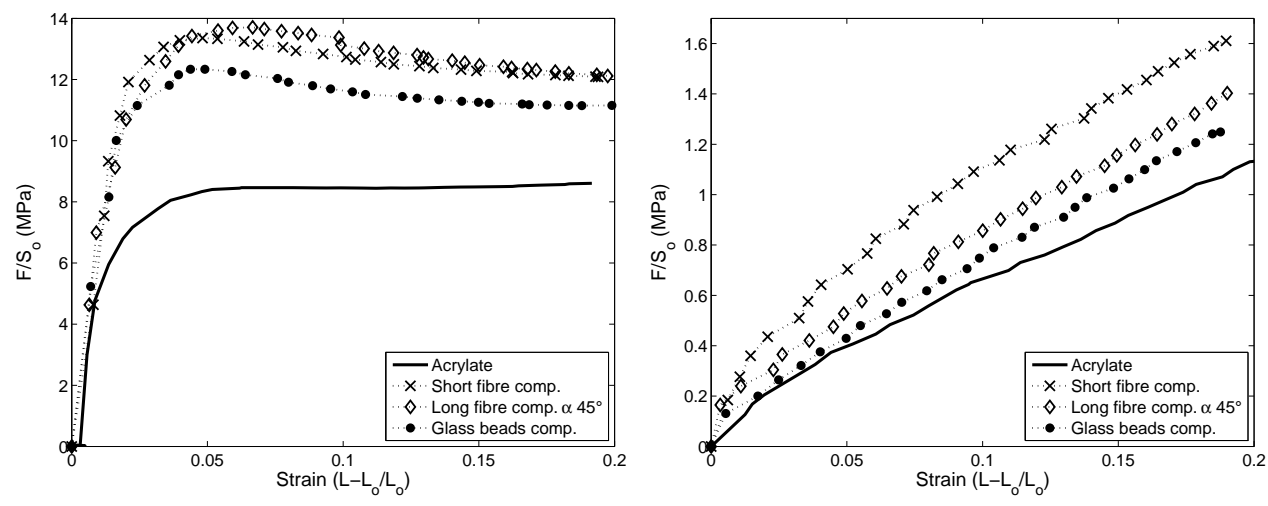

Figure 2. Uniaxial tension stress-strain responses measured at $45^{\circ} \mathrm{C}$ and at $65^{\circ} \mathrm{C}$.
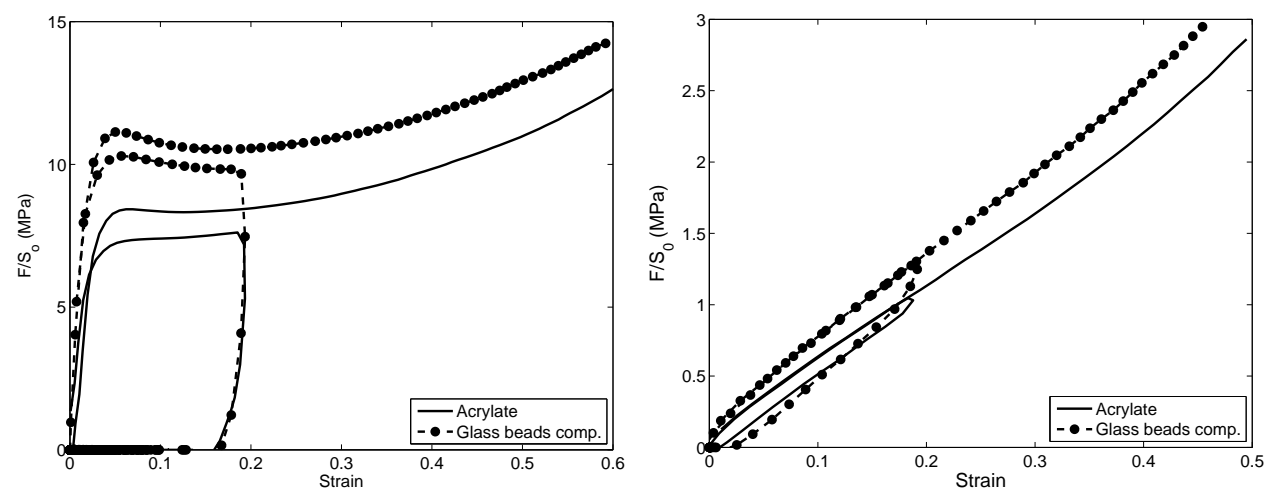

Figure 3. Load-unload-reload test for the glass bead composite and the plain acrylate at $45^{\circ} \mathrm{C}$ (left) and at $65^{\circ} \mathrm{C}$ (right).

at $45^{\circ} \mathrm{C}$ and $65^{\circ} \mathrm{C}$ but within very different durations, since two hours were needed for full recovery at $45^{\circ} \mathrm{C}$ when instantaneous recovery was observed at $65^{\circ} \mathrm{C}$. This feature is a signature of the temperature dependence of the polymer viscoelasticity.

\subsection{Shape recovery tests}

Free and constrained length recovery tests were performed in uniaxial tension, using an Instron 5881 machine. Shape recovery tests consist in: (i) applying $20 \%$ strain in uniaxial tension at $45^{\circ} \mathrm{C}$, (ii) maintaining the strain while cooling down the samples to room temperature, (iii) releasing stress to zero, and (iv) heating at a constant temperature rate of $1^{\circ} \mathrm{C} / \mathrm{min}$ or $5^{\circ} \mathrm{C} / \mathrm{min}$ in free or constrained length conditions. A graphic representation of the tests is shown in figure 4. It may be observed that stressfree length recovery and constrained-length stress recovery differ only at the last step, where either the strain is recorded in stress-free conditions or the stress is recorded in constrained-length conditions with respect to temperature. The temperature was measured accurately with a thermocouple placed close to the samples. The temperature of $45^{\circ} \mathrm{C}$ was chosen to apply strain since, the acrylate exhibits full strain recovery and high stress recovery at such a temperature (Arrieta et al. 2014b). 

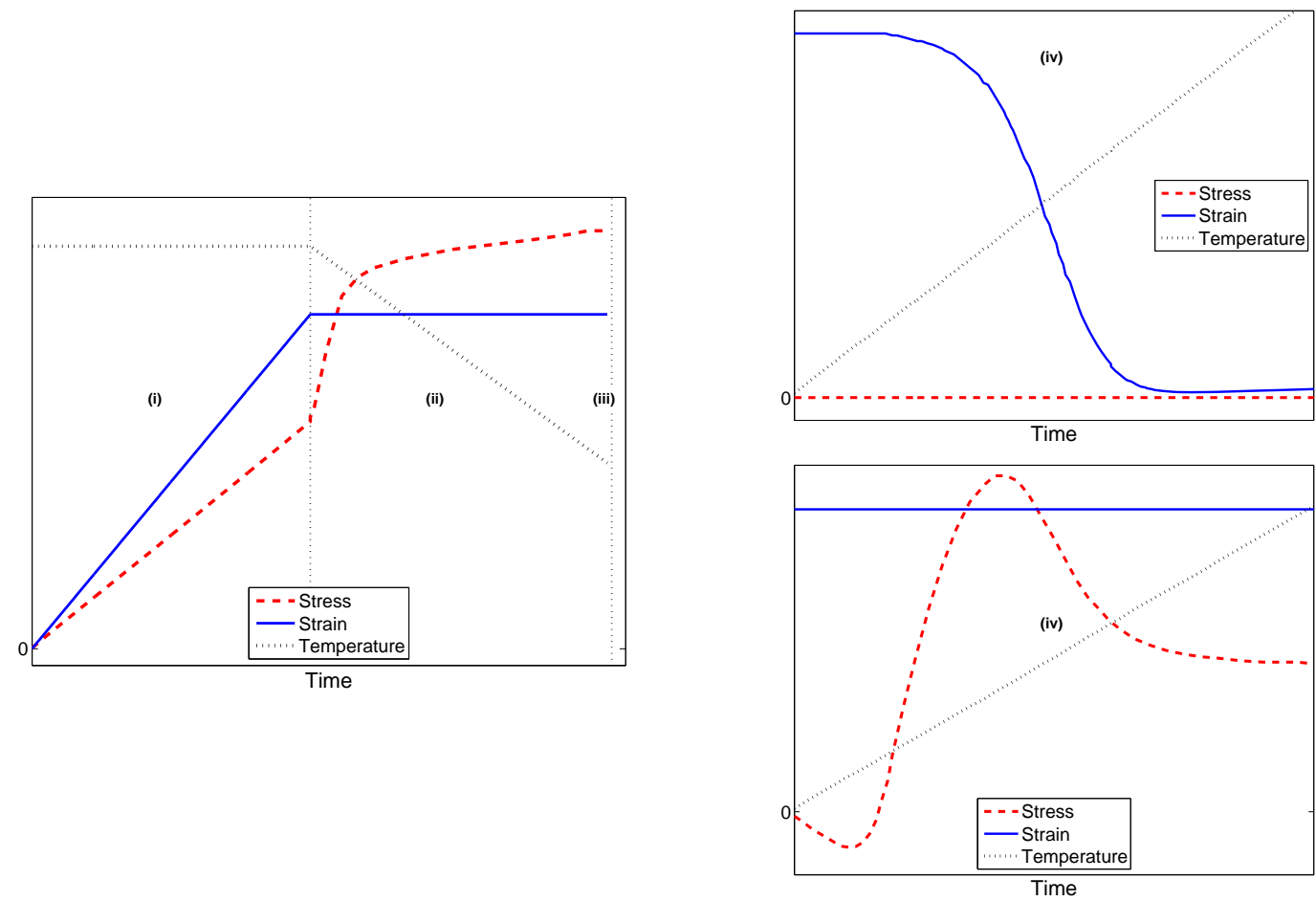

Figure 4. Thermomechanical recovery tests. Left: (i) uniaxial pre-stretching, (ii) cooling down to room temperature at constant strain, (iii) stress release. Right: (iv) stress-free length recovery (above) or constrained-length stress recovery (below), while heating the sample.

\section{Modelling}

\subsection{Thermomechanical behaviour of amorphous networks}

The shape memory property of amorphous polymer networks is due to the material viscoelasticity and to its time-temperature superposition property (Diani et al. 2012). The free-length strain recovery and the constrained-length stress recovery exhibited by the acrylate network have been successfully modelled (Arrieta et al. 2014a) by constitutive equations combining the finite strain viscoelastic model of Simo (1987), for which the relaxation times and the associated moduli of the generalized Maxwell viscoelastic model are extracted from standard small strain dynamic mechanical analysis tests, and by the WLF (Williams et al. 1955) equation to describe the timetemperature superposition. The acrylate network model parameters are reported in (Arrieta et al. 2014a). Since the constitutive equations were implemented in Abaqus (Abaqus/Standard 2010), a large spectrum of loading conditions and thermal histories were easily tested and confronted to experimental data.

\subsection{Finite element simulations}

The glass bead reinforced acrylate is modelled as an infinite periodic medium, with a cubic lattice of glass bead, as illustrated in figure 5a. Due to periodicity and to the 


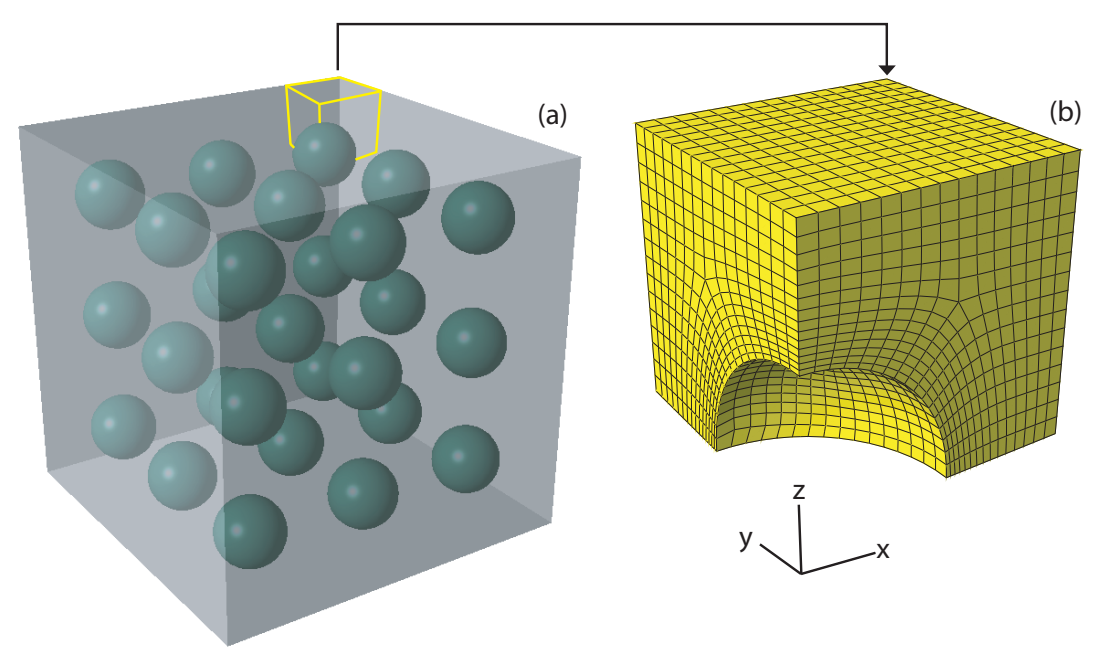

Figure 5. (a) Partial view of the infinite periodic medium used to represent the glass bead reinforced acrylate. (b) Meshed volume used in the simulations where uniaxial tension is applied along the $\mathrm{z}$ axis.

symmetry of the elementary cubic cell (where a bead is located at the center), a sufficient volume to study when uniaxial tension is applied parallel to a lattice axis is one eigth of the cubic cell. The 3D finite element mesh used for the matrix part is shown in figure 5b (4463 hexahedric C3D8H elements). The volume fraction of beads was chosen to $8 \%$ in order to well reproduce the observed experimental reinforcement (figure 6). Perfect adhesion between the glass bead and the matrix has been assumed. This assumption was motivated by the observed absence of damage noticed during experimental cyclic tests. Note that assuming poor adhesion at the matrix-bead interface almost cancels the reinforcement effect, therefore this assumption has been discarded. Consequently, keeping the nodes located on the spherical cap in figure 5b fixed is sufficient to model perfect adhesion to a rigid bead, and this is why no bead is shown in figure 5b. Standard symmetry boundary conditions are applied on the bottom, left, and front faces of the mesh. A uniform vertical displacement is prescribed to the nodes of the upper face, letting their $\mathrm{x}$ and $\mathrm{y}$ displacements free, in order to apply uniaxial tension. The right and back faces of the mesh are free to translate along the $x$ and $y$ axes, respectively, to model the lateral free surfaces of the specimen. Their nodes are left free to move in the plane of the face they belong to, which ensures periodicity. For simulations of the freelength and constrained-length recovery tests, every step from (i) to (iv) is simulated in order to correctly account for the whole loading history. Temperature is uniform over the whole mesh and the same history is applied as measured in the experiments. 


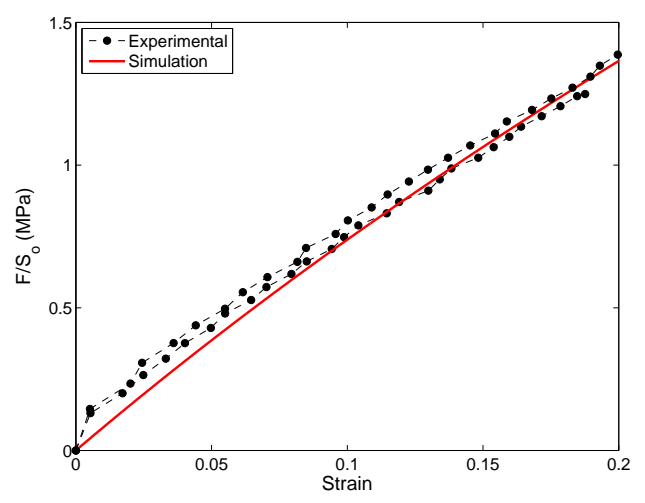

Figure 6. Comparison between the stress-strain behaviours at $65^{\circ} \mathrm{C}$ of the finite element simulation using representation Figure 5 and of the actual glass bead reinforced acrylate.

\section{Results and discussion}

\subsection{Experimental recovery tests}

4.1.1. Free and constrained length recovery of SMP composites: first results In this section, the plain acrylate and the SMPCs are submitted to the storage of $20 \%$ uniaxial strain applied at $45^{\circ} \mathrm{C}$. The free-length and constrained-length recoveries are recorded while heating the samples at $5^{\circ} \mathrm{C} / \mathrm{min}$ from room temperature to $65^{\circ} \mathrm{C}$. For free-length recovery tests, SMPCs and the plain acrylate showed full recovery. The recovery kinetics were similar, but with a slight shift toward higher temperatures for SMPCs (figure 7). Full strain or shape recovery for SMPCs has been reported already (Ivens et al. 2011, Fejos et al. 2012), and Liu et al. (2004) whose results show similar kinetics when comparing the free recoveries of a $\mathrm{SiC}$ reinforced epoxy and plain epoxy heated at $5^{\circ} \mathrm{C} / \mathrm{min}$. Therefore, knowing the recovery property of the polymer matrix may be enough to predict the shape recovery of the SMPCs, since it is likely to be close.

Figure 8 presents the stress vs. temperature history recorded during constrainedlength stress recovery tests. One notices that experimental results vary according to the material. The four materials exhibit the same curve shapes, but the curves are shifted significantly toward higher temperatures when fillers are added. Like Fejos et al. (2011) and Gall et al. (2002), one also observes an increase in the stress overshoot for reinforced polymers. Therefore, reinforcing SMPs may have a favorable impact for actuator applications, since it renders the material capable of generating larger forces. Figure 8 displays another interesting feature that has not been reported in the literature yet: the maximum compressive stress may be increased when adding fillers.

The change of recovery kinetics displayed by composites in figure 8 has not been observed by Gall et al. (2002). In order to better understand this result, further tests were run lowering the heating rate to $1^{\circ} \mathrm{C} / \mathrm{min}$ or adding a step of stress relaxation at $45^{\circ} \mathrm{C}$ after stretching the material. These test conditions were applied to the plain acrylate and to the glass bead reinforced acrylate only, since the experimental results 


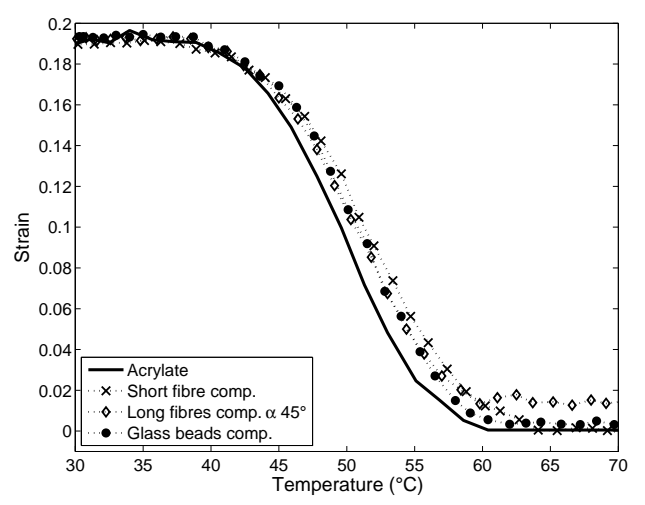

Figure 7. Stress-free length recovery comparison for samples pre-stretched $20 \%$ at $45^{\circ} \mathrm{C}$ heated at $5^{\circ} \mathrm{C} / \mathrm{min}$.

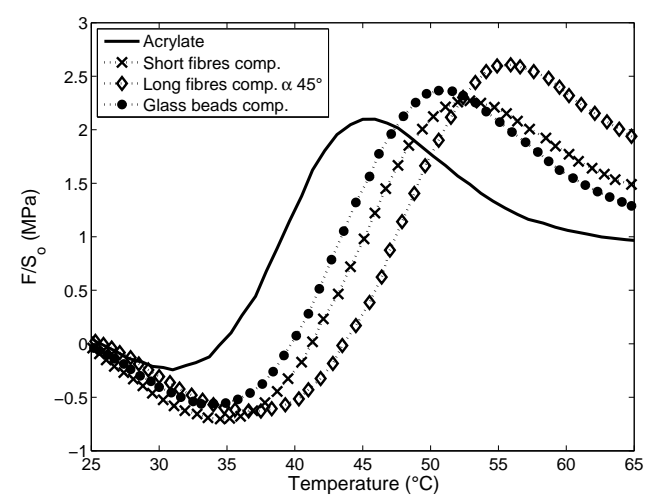

Figure 8. Constrained-length stress recovery comparison for samples pre-stretched $20 \%$ at $45^{\circ} \mathrm{C}$ and heated at $5^{\circ} \mathrm{C} / \mathrm{min}$.

obtained for these materials could be compared to the finite element simulations.

4.1.2. Glass bead reinforced SMP: additional results Figure 9 shows the comparison of the stress recovery measured on the plain acrylate and on the glass bead SMPC while heating the samples at $1^{\circ} \mathrm{C} / \mathrm{min}$. Contrary to previous results obtained at $5^{\circ} \mathrm{C} / \mathrm{min}$ and plotted in figure 8 , the stress recoveries exhibited by both materials are very similar but to the higher stress exhibited by the SMPC at high temperatures. This result is in good accordance with Gall et al. (2002). In general, an increase of the stress overshoot and the shift of the recovery curve toward higher temperatures have been observed for SMPs when the temperature heating rate is increased (Qi et al. 2008, Castro et al. 2010). This effect seems to be strengthened for the glass bead composite, where the recovery curve is even more shifted to higher temperatures and both the compression and tensile peaks are enhanced.

Finally, both materials were submitted to stress relaxation at fixed length during one hour at $45^{\circ} \mathrm{C}$ after stretching. Then, they were submitted to the same thermomechanical history, cooled down to room temperature at constant length, stress released, and constrained-length heating at $5^{\circ} \mathrm{C} / \mathrm{min}$. Stress recoveries with respect to 


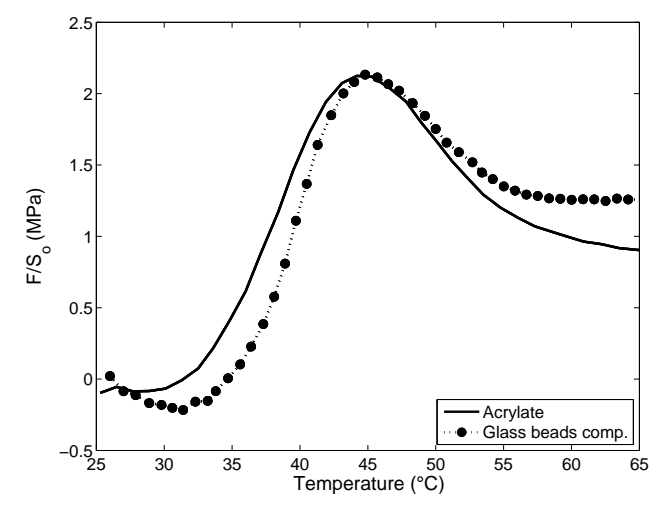

Figure 9. Constrained-length stress recovery comparison of the plain material and glass bead filled material pre-stretched $20 \%$ at $45^{\circ} \mathrm{C}$ and heated at $1{ }^{\circ} \mathrm{C} / \mathrm{min}$.

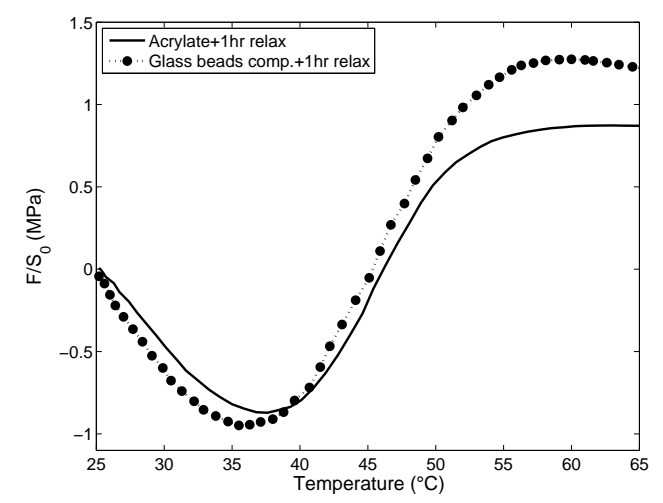

Figure 10. Constrained-length stress recovery for plain material and glass bead filled material after one hour of stress relaxation at fixed length at $45^{\circ} \mathrm{C}$ for samples prestretched at $45^{\circ} \mathrm{C}$ and heated at $5^{\circ} \mathrm{C} / \mathrm{min}$.

temperature are plotted in figure 10. The comparison of figure 8 and figure 10 shows the effects of a stress relaxation at high temperature on the stress recovery: a loss of stress overshoot, a larger compressive stress, and a shift of the recovery toward higher temperatures. Such effects have already been reported for plain SMPs (Nguyen et al. 2008, Castro et al. 2010, Arrieta et al. 2014b). Figure 10 extends them to SMPCs. Finally, stress relaxation at high temperature leads to similar stress recovery kinetics for SMPC and plain SMP. As a conclusion for the experimental data reported in the current study, one notices that:

- It is possible to reinforce SMP with various kinds of fillers and to keep their memory property,

- The shape recovery kinetics of reinforced SMPCs is very similar to the shape recovery of their SMP matrix material,

- The stress recovery exhibited by SMPCs may differ from the SMP matrix material according to the thermomechanical conditions,

- Slow heating and stress relaxation at high temperature after applying the temporary shape are in favor of obtaining the same recovery kinetics for SMPC and SMP. 
(a)

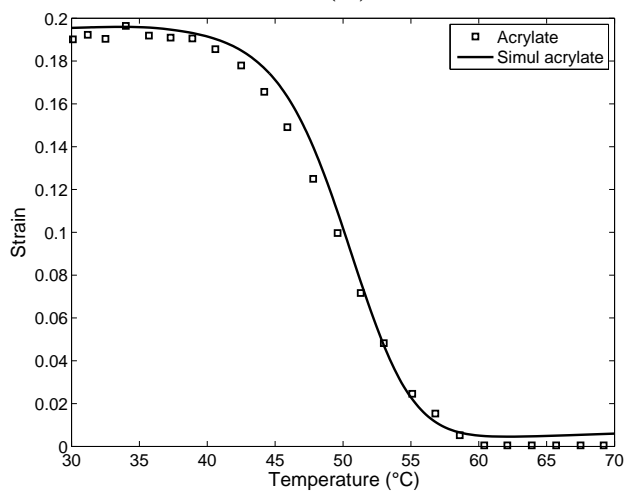

(b)

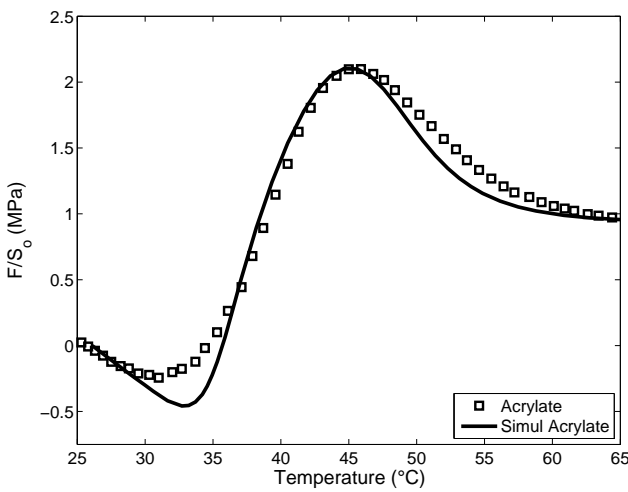

Figure 11. Comparison between model and experiments for plain acrylate prestretched $20 \%$ at $45^{\circ} \mathrm{C}$ and recovered in (a) stress-free length conditions at $5^{\circ} \mathrm{C} / \mathrm{min}$, and (b) constrained-length conditions at $5^{\circ} \mathrm{C} / \mathrm{min}$.

\subsection{Simulations}

4.2.1. Plain acrylate Figure 11 compares the model predictions and the experimental thermal recoveries for the plain acrylate network when heated at $5{ }^{\circ} \mathrm{C} / \mathrm{min}$. Good agreements between the model and the experiments are displayed. More results in Arrieta et al (2014a) assessed the prediction ability of the model for thermal recovery properties. Nonetheless, simulations and experiments have shown that constrainedlength stress recoveries are more sensitive to the thermal history, and therefore are more difficult to model accurately than stress-free length recoveries.

4.2.2. Glass bead filled acrylate In order to study the results provided by the modelled SMPC, its recovery properties are compared to those of the modelled plain SMP. Figure 12 presents the theoretical stress-free length thermal recoveries of the SMP and the $\mathrm{SMPC}$ when heated at $5^{\circ} \mathrm{C} / \mathrm{min}$. One notes that both recoveries superimpose perfectly. Therefore, finite element simulations with perfect adhesion of reinforced polymer will predict identical stress-free shape recoveries for the SMP and the SMPC. Analogous results were obtained by Alexander et al. (2013) when comparing theoretical stress-free strain recoveries obtained by $2 \mathrm{D}$ finite element simulations.

Figure 13 compares the simulations of constrained-length stress recoveries at $1^{\circ} \mathrm{C} / \mathrm{min}$ and $5^{\circ} \mathrm{C} / \mathrm{min}$. At $1^{\circ} \mathrm{C} / \mathrm{min}$, when comparing figure 9 and figure $13(\mathrm{a})$, it is to be noted that simulations are capable of reproducing the recovery kinetics observed experimentally, but to the fact that simulations predict a larger stress overshoot. This contrasts with the $5^{\circ} \mathrm{C} / \mathrm{min}$ heating ramp (figure $13(\mathrm{~b})$ and figure 8), where the stress peak is well reproduced, with no shift to higher temperatures though.

Therefore, simulations were unable to represent the experimental results showed in figure 8, which may be due to the too simple assumptions of a monodisperse and periodic distribution of fillers. 


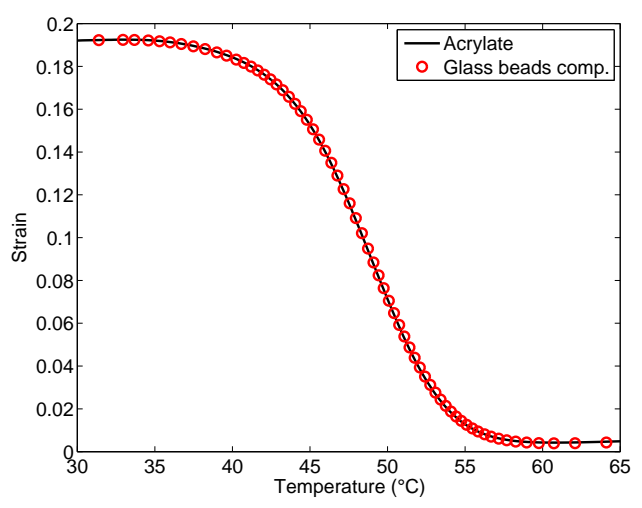

Figure 12. Stress-free length recovery simulations for the plain acrylate and glass bead filled composite for $20 \%$ pre-stretching at $45^{\circ} \mathrm{C}$ and recovered at $1{ }^{\circ} \mathrm{C} / \mathrm{min}$.

(a)

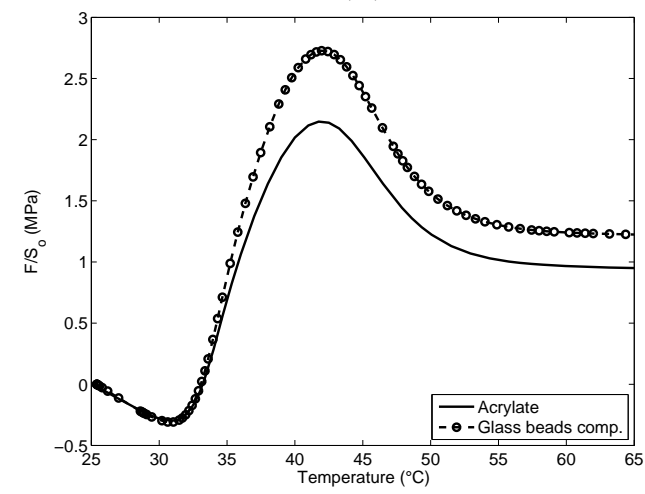

(b)

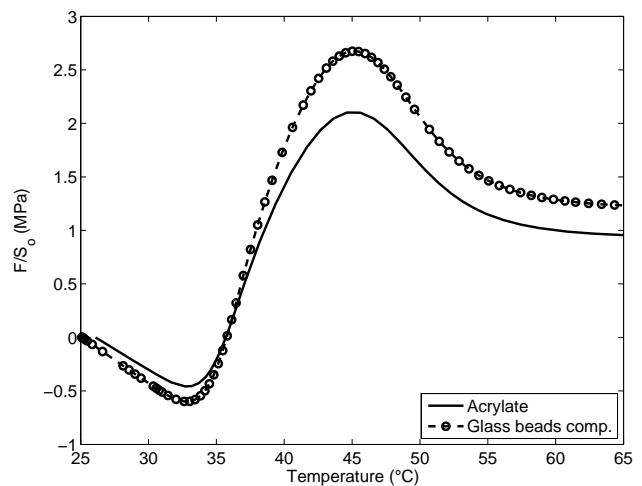

Figure 13. Constrained-length stress recovery simulations for samples pre-stretched $20 \%$ at $45^{\circ} \mathrm{C}$ and heated at (a) $1^{\circ} \mathrm{C} / \mathrm{min}$ and at (b) $5^{\circ} \mathrm{C} / \mathrm{min}$.

\section{Conclusions}

Recently, SMPs have been reinforced into SMPCs in order to circumvent some of their drawbacks, and to extend the development of these smart materials to new devices and applications. Reinforcements may produce stiffer and tougher materials in service and may also generate larger forces for actuator applications. In order to better characterize the effect of adding fillers on the recovery properties of SMPs, SMPCs were fabricated and tested in lab. It was shown that SMPCs can show excellent strain recovery properties. Moreover, the kinetics of stress-free length recovery displayed by the SMPCs is very similar to the recovery kinetics of their matrix material. Therefore, knowing the shape recovery properties of the polymer matrix allows predicting the shape recovery property of the SMPCs directly.

In SMPs, constrained-length stress recoveries have been known to be more sensitive to the thermal and loading histories, than stress-free recoveries. Experimental results show that this recovery feature is enhanced in SMPCs. The latter display a significant dependence of the constrained-length stress recovery with respect to the heating ramp. 
Nevertheless, its was shown that an SMPC and its polymer matrix material could show similar kinetics of stress recoveries when the parameters of the thermomechanical cycle were carefully chosen.

SMPCs are good candidates for finite element modelling. Based on the representation of the polymer matrix behaviour by viscoelastic finite strain constitutive equations combined with time-temperature superposition, and on the representation of the composite microstructure by a 3D periodic cell, the recovery properties of the glass bead reinforced SMPCs were simulated. It was observed that such a modelling leads to similar recovery properties for the SMPC and the SMP matrix for any thermomechanical loading conditions, which shows the limit of such a modelling.

\section{Acknowledgment}

This work was supported by the French "Agence Nationale de la Recherche" through the project REFORM 10-JCJC-0197. The authors gratefully thank L. Orgeas, from "Laboratoire Sols-Solides-Structures-Risques", CNRS - Université Grenoble (Grenoble INP / UJF) for providing the glass fibres used in this study.

\section{References}

Abaqus/Standard 2010 Dassault Systems Simulia Corporation. Providence, RI, USA.

Alexander S, Xiao R and Nguyen T 2014 Modelling the thermoviscoelastic properties and recovery behavior of shape memory polymer composites J. App. Mech. 81, 041003-1-041003-11.

Arrieta JS, Diani J and Gilormini P 2014 Experimental characterization and thermoviscoelastic modelling of strain and stress recoveries of an amorphous polymer network Mech. Mater. 68, 95-103.

Arrieta JS, Diani J and Gilormini P 2014 Cyclic and monotonic testing of free and constrained recovery properties of a chemically crosslinked acrylate J. App. Polym. Sci. 131, 39813-39820.

Azra C, Plummer C and Manson J 2011 Isothermal recovery rates in shape memory polyurethanes Smart Mater. Struct. 20, 082002-082011.

Cao F and Jana C 2007 Nanoclay-tethered shape memory polyurethane nanocomposites Polymer 48, 3790-3800.

Castro F, Westbrook K, Long K, Shandas R and Qi H 2010 Effects of thermal rates on the thermomechanical behaviors of amorphous shape memory polymers Mech. Time-Depend. Mat. 14, 219-241.

Cuevas JM, Rubio R, Laza JM, Vilas JL, Rodriguez M and León LM 2012 Shape memory composites based on glass-fibre-reinforced poly(ethylene)-like polymers Smart Mater. Struct. 21, 035004 .

Diani J, Gilormini P, Frédy C and Rousseau I 2012 Predicting thermal shape memory of crosslinked polymer networks from linear viscoelasticity Int. J. Solids Struct. 49, 793-799.

Ding J, Zhu Y and Fu Y 2013 Preparation and properties of silanized vapor-grown carbon nanofibers/epoxy shape memory nanocomposites Polym. Comp. 35, 412-417.

Fejos M, Romhany G and Karger-Kocsisi J 2012 Shape memory characteristics of woven glass fibre fabric reinforced epoxy composite in flexure J. Rein. Plast. Comp. 31, 1532-1537.

Gall K, Dunn ML, Liu Y, Finch D, Lake M and Munshi NA 2002 Shape memory polymer nanocomposites Acta Mater. 50, 5115-5126.

Hu J 2007 Shape memory polymers and textiles (Florida: CRC press INC). 
Ivens J, Urbanus M and De Smet C 2011 Shape recovery in a thermoset shape memory polymer and its fabric-reinforced composites Exp. Polym. Lett. 5, 254-261.

Kumar UN, Krats K, Behl M and Lendlein A 2012 Shape-memory properties of magnetically active triple-shape nanocomposites based on a grafted polymer network with two crystallizable switching segments Exp. Polym. Lett. 6, 26-40.

Lan X, Liu Y, Haibao L, Wang X, Leng J and Du S 2009 Fiber reinforced shape-memory polymer composite and its application in a deployable hinge Smart Mater. Struct. 18, 024002-024007.

Le HH, Kolesov I, Ali Z, Uthardt M, Osazuwa O, Ilisch S and Radusch HJ 2010 Effect of filler dispersion degree on the Joule heating stimulated recovery behaviour of nanocomposites $J$. Mater. Sci. 45, 5851-5859.

Lendlein A and Langer R 2002 Biodegradable, Elastic shape-memory polymers for potential biomedical applications Science 296, 1673-1676.

Leng J, Lan X, Liu Y and Du S 2011 Shape-memory polymers and their composites: Stimulus methods and applications Prog. Mater. Sci. 56, 1077-1135.

Li H, Zhong J, Meng J and Xian G 2013 The reinforcement efficiency of carbon naotubes/shape memory nanocomposites Composites part B 44, 308-516.

Liu Y, Gall K, Dunn M L and McCluskey P 2004 Thermomechanics of shape memory polymer nanocomposites Mech. Mater. 36, 929-940.

Liu Y, Du H, Liu L and Leng J 2014 Shape memory polymers and their composites in aerospace applications: a review Smart Mater. Struct. 23, 023001.

Lu H, Liu Y, Gou J, Leng J and Du S 2010 Electrical properties and shape-memory behavior of self-assembled carbon nanoviber nanopaper incorporated with shape-memory polymer Smart Mater. Struct. 19, 075021.

Meng H and Li G 2013 A review of stimuli-responsive shape memory polymer composites Polymer 54, 2199-2221.

Miaudet P, Derre A, Maugey M, Zakri C, Piccione P, Inoubli R and Poulin P 2007 Shape and temperature memory of nanocomposites with broadened glass transition Science 318, 12941296.

Nguyen T, Qi HJ, Castro F and Long KN 2008 A thermoviscoelastic model for amorphous shape memory polymers: Incorporating structural and stress relaxation J. Mech. Phys. Solids 56, $2792-2814$.

Ohki T, Ni Q-Q, Ohsako N and Iwamoto M 2004 Mechanical and shape memory behavior of composites with shape memory polymer Compos. Part A-Appl. S. 35 1065-1073.

Qi, H, Nguyen T, Castro F, Yakacki C and Shandas R 2008 Finite deformation thermo-mechanical behavior of thermally-induced shape memory polymers J. Mech. Phys. Solids 56, 1730-1751.

Razzaq MY, Anhalt M, Frormann L and Weidenfeller B 2007 Thermal, electrical and magnetic studies of magnetite filled polyurethane shape memory polymers Mater. Sci. Eng. A $444227-$ 235.

Safransky D and Gall K 2008 Effect of chemical structure and crosslinking density on the thermo-mechanical properties and toughness of (meth)acrylate shape memory polymer networks Polymer 49 4446-4455.

Simo J 1987 On a fully three dimensional finite strain viscoelastic damage model: Formulation and computational aspects Comput. Meth. Appl. M. 60, 153-173.

Weese J 1993 A regularization method for nonlinear ill-posed problems Comput. Phys. Commun. $77429-440$.

Williams M, Landel R and Ferry J 1955 The temperature dependence of relaxation mechanisms in amorphous polymers and other glass-forming liquids J. Am. Chem. Soc. 77 3701-3707.

Zhang C-S and Ni Q-Q 2007 Bending behavior of shape memory polymer based laminates Comp. Struct. 78 153-161.

Zhou B and Liu Y-J 2009 A glass transition model for shape memory polymer and its composite Int. J. Mod. Phy. B 23 1248-1253. 